\title{
Os Sintomas da Síndrome de Burnout Adquiridos pelos Estudantes de Secretariado Executivo
}

Burnout Syndrome Symptoms Acquired by Executive Secretariat Students

Alexandre Oliveira Silva de Jesus ${ }^{1}$ e Cibelle da Silva Santiago ${ }^{2}$

1,2Universidade Federal da Paraíba, UFPB 


\title{
Resumo
}

A síndrome de Burnout é conhecida como um distúrbio apresentado por um indivíduo que tem a sua energia exaurida, devido à má adaptação a um trabalho prolongado e muito estressante. Este trabalho teve como objetivo geral investigar se os estudantes de Secretariado Executivo têm conhecimento dos sintomas da Síndrome de Burnout. Esta pesquisa foi de cunho bibliográfico e exploratório e de campo, sob a abordagem de métodos mistos quanti-qualitativos. Os dados foram coletados por meio de questionário on-line gerado no Google Formulários e encaminhado aos graduandos dos cursos de Secretariado Executivo de diferentes instituições de ensino superior do Brasil, utilizando e-mail e as redes sociais Facebook e WhatsApp, em que se obteve um retorno de 251 respostas. Para análise e discussão dos resultados, foram utilizadas as análises com estatística descritiva e de conteúdo. Como principais resultados, verificou-se que a maioria dos respondentes não têm conhecimento sobre os sintomas da Síndrome de Burnout, o que dificulta compreender e buscar apoio psicológico dentro ou fora da universidade.

Palavras-chave: saúde mental, ansiedade, universitários

\begin{abstract}
Burnout syndrome is known as a disorder presented by an individual whose energy is depleted caused by its excessive and extended stress when not well-adapted to a certain kind of work. This work aimed to raise Executive Secretariat students' awareness of Burnout Syndrome symptoms. The following study was a bibliographical, exploratory, and field research with both quantitative and qualitative methods. Data were collected through online questions created on Google Forms and sent to the Executive Secretariat college students from different Higher Education Institutions in Brazil, using email and social networks Facebook and WhatsApp, obtaining 251 answers in total. It was applied to descriptive statistics and content analysis to inquire and discuss results. As its main results, it was observed that most of the students were not aware of Burnout Syndrome symptoms, which may turn it difficult to comprehend and ask for psychological support whether inside or outside the university. Keywords: mental health, anxiety, college students
\end{abstract}


Diariamente, estudantes universitários são imersos em diversas atividades acadêmicas, sejam curriculares ou extracurriculares. Tais atividades são previstas nas concepções do Projeto Pedagógico do Curso, bem como a complexidade necessária para a formação do secretário executivo com a inclusão de disciplinas de várias áreas do conhecimento, visando capacitar este profissional para atuar no mercado de trabalho (Gerardin Júnior, Monteiro \& Gianini, 2011).

Nesse sentido, entende-se que as atividades curriculares são oriundas das disciplinas que os estudantes estão cursando. Já as atividades extracurriculares, também denominadas complementares ou não obrigatórias, incluem a participação em monitoria, iniciação científica, projetos de extensão, grupos de estudos e pesquisa, nos órgãos de representação estudantil, em congressos e eventos científicos, estágios remunerados ou não remunerados, entre outras (Bardagi \& Hutz, 2012).

Partindo do pressuposto de que as atividades desenvolvidas no âmbito acadêmico podem ser geradoras de emoções positivas e negativas, aponta-se a necessidade da busca do autoconhecimento pelos alunos, visando explorar sentimentos para compreender as emoções, principalmente as negativas que são estimuladas pelas atividades acadêmicas. Vê-se, aqui, a dificuldade em gerenciar emoções negativas, devido à ausência de autoconhecimento e ciência das causas que provocaram tais emoções. Além desse desconhecimento, algumas atividades curriculares de cunho didático-pedagógicas são de caráter avaliativo e, portanto, deverão gerar uma nota para que se mensure o desempenho do aluno. Ao se encontrar numa situação de avaliação, estudantes universitários experimentam sentimentos e emoções que afetam o seu comportamento psicológico e, também, físico.

Destaca-se que o início da vida acadêmica desperta no estudante alterosas expectativas com tal universo, devido à falta de conhecimento que a grande maioria tem sobre a rotina e os relacionamentos que estão por vir. Ao ingressar na universidade, o estudante se depara com situações e atividades que lhe são impostas/cobradas a fim de desenvolver suas habilidades e competências para adentrar no mercado de trabalho. Vislumbrando o leque de competências que são exigidas de um profissional de secretariado, tem-se a inteligência emocional como um fator extremamente importante para o bom desempenho e saúde do profissional.

Sobre isso, Weisinger (2001, p. 14) diz que a "Inteligência Emocional é simplesmente o uso inteligente das emoções, isto é, fazer intencionalmente com que suas emoções trabalhem a seu favor, usando-as como uma ajuda para nortear seu comportamento e raciocínio de maneira a aperfeiçoar seus resultados". Não obstante, a inteligência emocional deve ser uma habilidade característica do profissional de secretariado executivo, porém, acredita-se que ela já deva ser explorada e gerenciada durante a vida universitária, visando evitar problemas de saúde, como a depressão e outros transtornos psicológicos. Inúmeros estudantes podem passar por situações complicadas devido à grande quantidade de atividades acadêmicas que são demandadas, concomitantemente, por várias disciplinas durante o semestre de aula.

Nesse contexto, a problemática que norteou esta pesquisa está centrada nos sintomas da Síndrome de Burnout que os estudantes, possivelmente, adquiriram quando ingressaram na universidade. A junção do excesso 
de tarefas com a má gestão emocional pode provocar casos de exaustão e estresse, desencadeando a síndrome de Burnout. Esta síndrome é conhecida como um distúrbio apresentado por um indivíduo que tem a sua energia exaurida, devido à má adaptação a um trabalho prolongado e muito estressante (Garcia \& Benevides-Pereira, 2003). Justifica-se a necessidade deste estudo para que os estudantes possam se autoavaliar, tentando enxergar as emoções vivenciadas a partir das atividades realizadas no âmbito acadêmico, além de compreenderem o quanto é necessário conhecerem estratégias para gerenciar e desenvolver a inteligência emocional na universidade.

Sobre isso, determinados estudos publicados afirmam que Burnout é uma síndrome que afeta profissionais de diversas áreas, sendo considerada um problema que atinge, sobretudo, os trabalhadores que se sentem sobrecarregados e estressados, sentimentos e ações consideradas negativas em relação ao emprego Lima (2007 como citado em Rocha \& Santos, 2014, p. 2). Todavia, já existem outras investigações realizadas e publicadas que tiveram como público-alvo os estudantes de diversos cursos de graduação como, por exemplo: Enfermagem (Borges \& Carlotto, 2004; Galindo, Feliciano, Lima \& Souza, 2016; Barboza \& Beresin, 2007; Fisioterapia (Christofoletti, Trelha, Galera \& Feracin, 2007); Psicologia (Carlotto \& Câmara, 2008); Ciências Contábeis (Guimarães, 2014). Tais estudos confirmaram o aparecimento de sinais da Síndrome de Burnout nos respectivos universitários, desencadeando no distanciamento dos estudos e comprometendo a busca da eficácia profissional.

Na área de Secretariado Executivo não foram encontrados estudos com essa temática. Cotidianamente, universitários precisam lidar com diversas atividades acadêmicas, sejam elas originárias das disciplinas, sejam de atuações extraclasse como monitorias, projeto de extensão e pesquisa, dentre outras. "A inserção dos estudantes no contexto da pesquisa e da extensão, promovendo certo exagero e exacerbação de tarefas acadêmicas, tem sido responsável pelo surgimento de sintomas característicos da Síndrome de Burnout (Mota, Farias, Silva \& Folle, 2017, p. 246)".

Por isso, essa pesquisa revela-se inovadora e pioneira, sendo o recorte de uma investigação mais ampla que, a priori, tem a seguinte questão de investigação: Os estudantes de Secretariado Executivo do Brasil adquiriram algum sintoma relacionado à síndrome de Burnout após ingressarem na universidade? Nesse sentido, o objetivo geral é apontar os sintomas da síndrome de Burnout que os estudantes de Secretariado Executivo do Brasil possam ter adquirido após ingressarem na universidade; conhecer os fatores que causaram estresse aos estudantes de Secretariado Executivo durante a vida acadêmica.

\section{A Inteligência Emocional e o Contexto da Síndrome de Burnout}

De acordo com King (2016), a inteligência emocional (IE) é uma habilidade pessoal que permite detectar, administrar e demonstrar suas emoções de um modo a alcançar o equilíbrio das relações interpessoais com empatia e de forma cautelosa. A inteligência emocional; auxilia na percepção e compreensão das emoções, devendo o sujeito reagir a determinadas situações com inteligência e comportamento racional na gestão dos sentimentos a favor dos interesses pessoais e coletivos. Além disso, a IE também ajuda na identificação das emoções demonstradas pelos indivíduos com quem nos relacionamentos, ou seja, ela serve como uma ferramenta para avaliar e refletir as emoções que são expostas. 
Agir de maneira inteligente com suas emoções é comportar-se de forma eficaz, empática e adequada, tendo autocontrole emocional. Para isso, é necessário desenvolver e aprimorar algumas habilidades específicas como, por exemplo, as citadas por Walton (2016): 1) Controlar as próprias emoções; 2) Demonstrar empatia em relação ao sentimento dos outros; 3) Usar habilidades sociais de maneira efetiva e agradável; 4) Desenvolver Inteligência emocional; 5) Conhecer razoavelmente bem a si mesmo. Essas habilidades devem ser trabalhadas, também, pelos estudantes de graduação afim de que os sentimentos que são gerados a partir da vivência no âmbito universitário sejam administrados, visando diminuir ou prevenir impactos negativos para a própria saúde mental e física.

Os indivíduos, para adquirirem uma inteligência emocional, deve conhecer suas características pessoais, as situações que lhe causam prazer e desconforto, as relações interpessoais que estimulam o sofrimento psíquico. Existem diversas emoções que compõem a formação da personalidade do indivíduo e do caráter como, por exemplo, raiva, compaixão, coragem, cordialidade, ansiedade, calma, angústia, ânimo, apatia, alegria, tristeza, confiança, estima, sinceridade, amizade, estresse, frustração, felicidade, dentre outros. Esses sentimentos podem ser separados em emoções positivas e negativas. Os sentimentos positivos devem ser cada vez mais desenvolvidos e aflorados. Já os negativos, segundo Valle (2016), precisam ser dominados e monitorados para que não afetem ao próprio indivíduo que o possui e, também, as pessoas que estão ao seu redor.

Todas as emoções são, em essência, impulsos, legados pela evolução, para uma ação imediata, para planejamentos instantâneos que visam lidar com a vida. A própria raiz da palavra emoção é do latim movere — "mover" - acrescida do prefixo "e-", que denota "afastar-se", o que indica que em qualquer emoção está implícita uma propensão para um agir imediato (Goleman, 2011, p. 34).

Ferreira (2016) afirma que os profissionais, atualmente, precisam saber, aprender e ter o domínio sobre as técnicas da inteligência emocional, considerando que vivemos em uma sociedade com elevados níveis de estresse e com grandes números de desastres causados pelo descontrole das emoções. É necessário detectar e filtrar os fatores causadores do estresse e irracionalidade, realizar uma limpeza e reciclagem de pensamentos, mudar positivamente algumas perspectivas e direcionamentos do cotidiano, e envolver-se com o aperfeiçoamento da própria personalidade e capacidades através do autoconhecimento e da autogestão das emoções.

Trazendo esses conhecimentos para o âmbito acadêmico, os indivíduos podem detectar, analisar e gerir as emoções de forma positiva. Tendo em vista que, diariamente, vivenciamos diferentes situações e atividades na universidade, faz-se necessário utilizar cada experiência para aprimorar a inteligência emocional e a percepção em relação aos sentimentos individuais e coletivos que são gerados. Trabalhando de tal forma, é possível evitar desgastes na saúde e ao mesmo tempo preparar-se profissionalmente para conseguir a inserção no mercado de trabalho.

Um fator que contribui para gerenciar as emoções é o autoconhecimento que, segundo Goleman (2015), configura-se em uma forte percepção das próprias emoções, forças, pontos francos, necessidades e impulsos. As pessoas que não se conhecem vivenciam momentos emocionais sem maturar e refletir os impactos causados 
devido às essas emoções experienciadas. Sendo assim, um indivíduo ou profissional que não conhece a si mesmo, pouco se desenvolverá e, tampouco, conseguirá identificar e conhecer os aspectos emocionais.

Ao contrário de reprimir, a boa gestão das emoções tem como objetivo entendê-las e usar tais compreensões para enfrentar situações de forma mais proveitosa e tentar prevenir algumas síndromes, como a de Burnout. Ela se configura como um estado de esgotamento, decepção, perda do interesse pela atividade de trabalho, manifestando-se em profissionais que, em seu dia a dia, trabalham diretamente com pessoas (BenevidesPereira, 2003). Na década de 70, Maslach (1993 como citado em Castro \& Zanelli, 2007 p. 17), ao investigar a carga emocional do trabalho de profissionais de enfermagem, médicos, assistentes sociais e advogados, apurou que a expressão "burnout" (ser consumido, queimado pelo emprego) era geralmente utilizada para expressar um cansaço emocional gradativo e a falta de comprometimento com as exigências e as demandas elevadas no trabalho.

A teoria revela que os trabalhadores, que apresentam a síndrome, encontram-se com seus recursos emocionais esgotados e desenvolvem atitudes cínicas e sentimentos negativos para lidar com suas práticas profissionais. Ao mesmo tempo em que manifestam sentimentos negativos em relação às pessoas que os circundam, estes trabalhadores fazem uma avaliação negativa de si mesmo, manifestando, consequentemente, insatisfação com sua atividade (Mota et al., 2017, p. 248).

Bueno (2017) classifica os sintomas da síndrome de Burnout em quatro formas: 1. Física: refere-se à fadiga, distúrbio, dores musculares, falta de apetite; 2. Psíquica: concernente à falta de atenção, alterações de memória, ansiedade e frustração; 3. Comportamental: diz respeito à negligência e suas responsabilidades, irritabilidade ocasional ou instantânea, concentração alterada, aumento de conflitos com colegas; descumprimento de horário de trabalho; 4. Defensiva: baixo rendimento.

A síndrome de Burnout possui diferentes estágios de manifestação, constância e intensidade. Sendo assim, trata-se de um processo gradativo e de efeito cumulativo. Em relação à frequência, o estágio inicial ocorre com o surgimento eventual dos sintomas, já o estágio avançado caracteriza-se por apresentar os sintomas de forma permanente. Em relação aos sintomas mais avançados, esses caracterizam-se pelo surgimento de doenças e somatizações Maslach \& Leiter (1999 como citado em Palazzo, Carlotto \& Aerts, 2012, p. 70).

Segundo Maslach \& Jackson (1981), a Síndrome de Burnout explica-se teoricamente por três componentes: exaustão emocional, despersonalização, realização profissional. A exaustão emocional é caracterizada por um sentimento muito forte de tensão que produz sensação de esgotamento, de falta de energia e de recursos emocionais para lidar com as rotinas a que os indivíduos estão submetidos, seja referente à prática profissional ou à vida acadêmica. A despersonalização é resultado do desenvolvimento de sentimentos e de atitudes negativas em relação àquelas pessoas que entram em contato direto com o sujeito que está no âmbito de sua atuação, seja no mercado de trabalho, seja na universidade. A falta de realização profissional se caracteriza pela tendência de estar insatisfeito com as condições que afetam as habilidades interpessoais e que influenciam, diretamente, na forma de atendimento e de contato com os colegas de classe ou do trabalho e, também, com os professores. Entende-se que 
a síndrome de Burnout está associada a consequências que reverberam no comportamento físico e mental do ser humano, podendo estimular outros distúrbios e, inclusive, provocar o suicídio.

\section{Procedimentos Metodológicos}

Quanto aos objetivos, os procedimentos metodológicos desta pesquisa são bibliográficos, exploratórios e documentais. A pesquisa bibliográfica amparou-se, principalmente, nos teóricos que tratam das metodologias pedagógicas de avaliação no ensino superior (Luckesi, 1997) e da síndrome de Burnout (Maslach e Jackson, 1981) e (Olivo e Bueno, 2017) utilizando, principalmente, os artigos científicos publicados no portal de periódicos da SciELO.

A pesquisa exploratória é caracterizada por investigar fenômenos de uma determinada temática. Gil (2006, p. 43) diz que a pesquisa exploratória “[...] é realizada especialmente quando o tema escolhido é pouco explorado e torna-se difícil sobre ele formular hipóteses precisas e operacionais". A temática da síndrome de Burnout não tem sido abordada em outros estudos da área secretarial, motivo pelo qual se faz necessário identificar e examinar os fenômenos e sintomas que podem ocorrer nos estudantes dos cursos de Secretariado Executivo do Brasil, além de que os estudos envolvendo esta síndrome e a comunidade acadêmica em nível de graduação são poucos explorados.

A abordagem para a coleta de dados é de métodos mistos, tendo em vista que análises quantitativas como qualitativas serão empregadas em conjunto para melhor compreensão do fenômeno estudado (Creswell, 2007). Para consolidar o objetivo, foi utilizado um questionário em formulário on-line como instrumento de coleta de dados, elaborado a partir da ferramenta do Google, o formulário Google Docs. O questionário é uma “investigação composta por um número [...] elevado de questões apresentadas [...] às pessoas, tendo por objetivo o conhecimento de opiniões, crenças, sentimentos, interesses, expectativas, situações vivenciadas etc." (Gil, 2006, p. 128).

Para alcançar os sujeitos da pesquisa foi feita uma busca dos grupos formados em redes sociais de diversos cursos de Secretariado Executivo no Brasil. Com isso, o questionário foi enviado por e-mails e grupos específicos das redes sociais Facebook e WhatsApp para inúmeros estudantes, no período de 09 a 15 de janeiro de 2019. Utilizou-se a amostragem por conveniência para uma população infinita com a margem de erro de 5,2 para mais ou para menos ao nível de $90 \%$ de confiança. Isto significa que considerando a margem de erro, a chance de o resultado retratar a realidade é de $90 \%$. Para a definição do tamanho da amostra foi considerado como sendo uma população infinita, uma vez que os dados sobre a quantidade de alunos ativos dos cursos de Secretariado Executivo, no Brasil, não eram de fácil acesso.

De posse das respostas dos questionários devidamente tabuladas com o suporte do Microsoft Excel, foram utilizadas a análise estatística descritiva e de conteúdo. Para a análise estatística descritiva, analisaram-se os dados por meio da variância e porcentagem. Usou-se a porcentagem, de modo que os dados foram apresentados em forma de gráficos do tipo barra e pizza e técnicas estatísticas de distribuição de frequências absolutas e relativas, para efeitos de mensuração do nível de estresse sentido pelos estudantes, de modo que se utilizou a análise estatística descritiva para discutir os dados. 
A análise de conteúdo "compreende técnicas de pesquisa que permitem, de forma sistemática, a descrição das mensagens e das atitudes atreladas ao contexto da enunciação, bem como as inferências sobre os dados coletados" (Cavalcante, Calixto, Pinheiro \& 2014, p. 14). Desta feita, foi possível dialogar com os dados coletados e alguns teóricos, estando os resultados apresentados em forma de quadros, figuras e tabelas para que fiquem mais claros e facilitem o entendimento da análise, além de permitir que o leitor crie suas próprias interpretações a partir das respostas, sistematicamente expostas.

\section{Análise e Discussão dos Resultados}

Os dados coletados por meio de questionário on-line foram analisados e discutidos com o propósito de identificar os níveis de estresse apresentados pelos estudantes dos cursos de Secretariado Executivo em diversas regiões do Brasil, de acordo com as metodologias de avaliação. Obteve-se um retorno de 251 respostas, sendo $81,7 \%$ identificadas como gênero feminino e $18,3 \%$ como gênero masculino. A amostra foi considerada representativa, com a margem de erro de 5,0 para mais ou para menos ao nível de $95 \%$ de confiança. Isto significa que considerando a margem de erro, a chance de o resultado retratar a realidade é de $95 \%$.

Adiante, na figura 1, os estudantes apontaram os sintomas de Burnout que avaliam ter adquirido durante a vida acadêmica: Ansiedade, 64,5\%; cansaço, 62,2\%; Sensação de esgotamento físico com 57,8\%; irritabilidade, $51,8 \%$; sentimento de incapacidade ou inferioridade $50,2 \%$.

\section{Figura 01}

Sintomas da síndrome de Burnout adquiridos pelos estudantes após ingressar na universidade

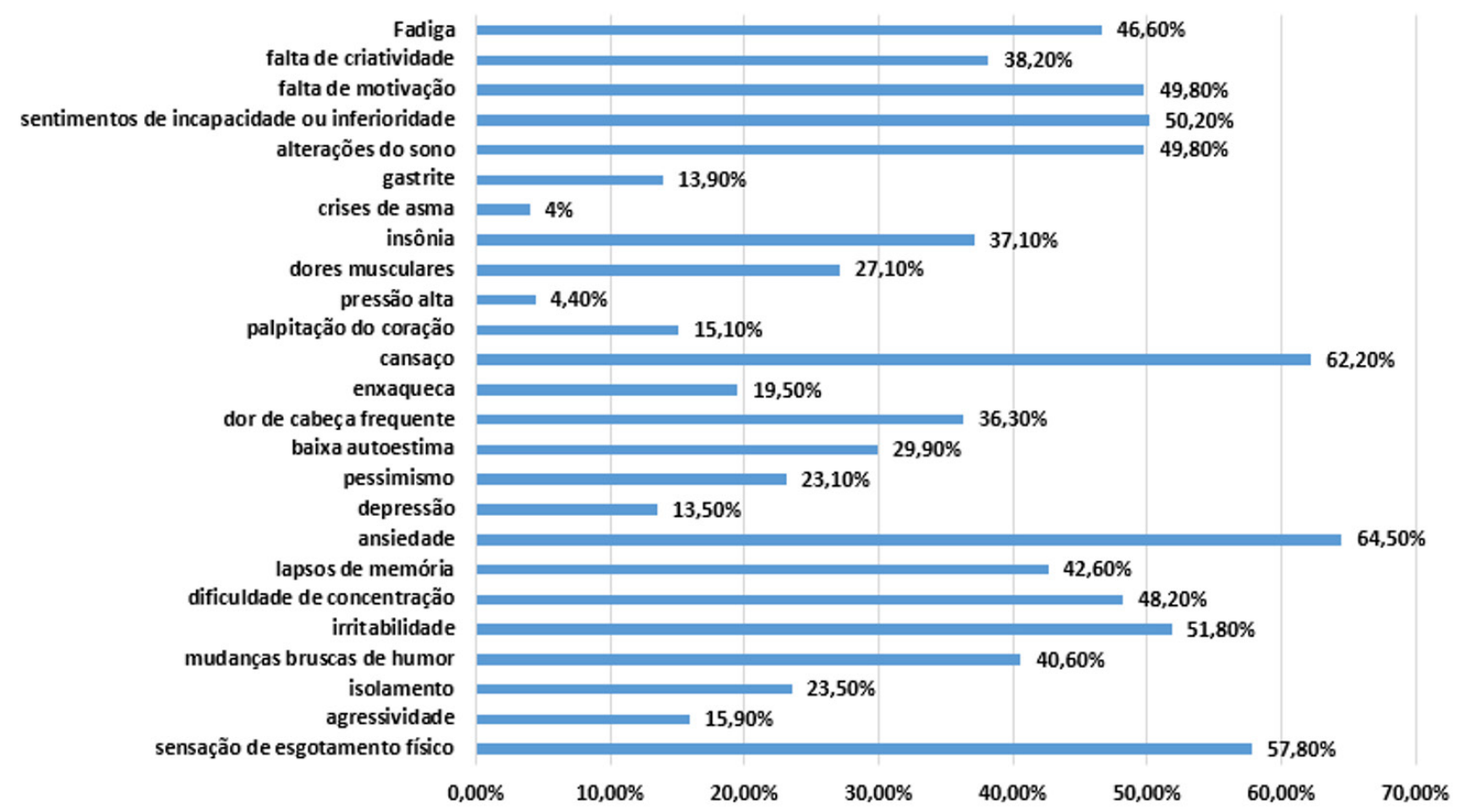

Nota: Elaborado pelos autores

Os sintomas destacados acima apresentam características que estão associadas à tensão da vida cotidiana, especificamente no meio universitário. Por ser considerada um dos principais problemas que afetam a saúde do ser humano, a ansiedade foi a mais pontuada pelos estudantes de Secretariado Executivo como um dos sintomas adquiridos durante a vida universitária. 
Os transtornos de ansiedade são considerados um dos principais problemas de saúde mental dos brasileiros e estão entre os transtornos psiquiátricos mais frequentes na população. É provavelmente a disfunção emocional que mais aflige e que mais atinge a qualidade de vida do indivíduo. São considerados os transtornos mais incapacitantes Ramos (2009 como citado em Albornoz, 2016, p. 10).

Entende-se que a ansiedade é provocada pelas cargas emocionais que são demandadas na gestão das atividades curriculares e extracurriculares do curso, além da exigência de se assumir uma postura mais profissional durante os estágios no sentido de conseguir integrar a teoria com a prática. Existem alguns outros transtornos que podem ser desencadeados a partir da ansiedade como: Transtorno do Pânico-caracterizado por medo inesperado e intenso; Transtorno Agorafobia- "que se caracteriza por situações em que possa ser difícil ou embaraçoso sair, podendo desencadear ataques de pânico (ônibus, aviões, cinema, reuniões, etc.) ou, ainda, situações em que a ajuda não esteja disponível" (Zuardi, 2017).

A ansiedade, também, está relacionada ao fato de diversos estudantes universitários precisarem sair do seio familiar para estudar em outros locais. O afastamento de casa, dos objetos pessoais, dos pais e dos amigos contribuem para que o estudante tenha dificuldades de rápida adaptação, misturando a ansiedade e o humor depressivo (Thurber \& Walton, 2007). Considerando que a comunidade acadêmica poderá ser considerada como um novo clã para os estudantes que vêm de outras regiões, é imprescindível que eles sejam bem acolhidos pelos docentes, servidores técnico-administrativos e a própria sociedade civil, visando aumentar os sentimentos que lhe causem bem-estar, equilíbrio emocional e estabilidade afetiva.

Em complemento, os estudantes alegaram que passaram a sentir cansaço, experimentar sensação de esgotamento físico e irritabilidade a partir do seu ingresso na universidade. O cansaço e o esgotamento físico podem estar relacionados, também, à ausência de sono qualitativo. Quando um indivíduo dorme mal pode apresentar fadiga, cansaço, tensão, diminuição no rendimento intelectual, sintomas de depressão, ansiedade, sonolência diurna, dores musculares e irritabilidade, efeitos que se intensificam com a quantidade de noites mal dormidas, podendo se amenizar ou desaparecer após noites bem dormidas (Tavares, 2002). A falta de repouso suficiente, certamente, influencia na qualidade das atividades desempenhadas, exigindo um nível maior de atenção e concentração, o que poderá provocar cansaço e esgotamento físico demasiado.

O ritmo de vida mais intenso, alta carga horária de estudos, o distanciamento da família em determinados períodos do dia, a imposição de prazos para a execução das atividades, têm provocado nos universitários sentimentos de estresse, impaciência e irritabilidade. Deve-se ter atenção com a irritabilidade constante do aluno, pois ela é um dos sintomas da síndrome de depressão (Ribeiro, Honrado \& Leal, 2004), que, se não for tratada, pode provocar atos de suicídios como alternativas mais viáveis para a resolução de problemas e conflitos psicossomáticos (Barbosa, Macedo \& Silveira, 2011).

Por fim, o sentimento de incapacidade ou inferioridade pode estar diretamente ligado às frustrações. “O sentimento de inferioridade é, de início, normal em todos nós, já o Complexo de Inferioridade deve ser compreendido como uma condição patológica, encontradiço em algumas pessoas (Teixeira, 1960, p. 83-84). 
Quando uma atividade é atribuída pelo professor ao longo das disciplinas, o estudante tende a se esforçar para que os critérios de avaliação previamente estabelecidos sejam cumpridos. Todavia, quando o estudante não consegue lograr êxito seja por: a) não compreender totalmente a tarefa; b) não ter tempo suficiente para se dedicar aos estudos; c) receber influências e interferências que estão além do seu domínio, ele pode apresentar sentimentos inferiores em relação aos apresentados pelos demais colegas de classe.

Quando o sentimento de inferioridade é originado pela situação econômica, alimentação inadequada, carência de sentimentos a que está submetido ou à ausência de sentimentos, Adler (1930/1948 como citado em Leal \& Antunes, 2015) afirma que pode ocorrer a contenção do desenvolvimento de sentimentos altruístas, bem como a sociabilidade e a confiança na sociedade humana ao se deparar com as dificuldades que lhe são impostas ou para resolver tais situações.

Na sequência, na figura 2, perguntou-se aos estudantes os fatores específicos que fazem parte da rotina acadêmica que, porventura, provocaram estresse. Conforme dados apresentados, vê-se que os fatores mais pontuados são: sentimentos de perfeccionismo/autoexigência, 62,9\%; excessiva carga de estudo imposta, 60,6\%; conciliar estudo e lazer, 49,4\%; preocupação quanto à colocação profissional, 48,2\%; necessidade de participação simultânea em projetos de ensino, pesquisa e extensão, 39,8\%.

Os sentimentos de perfeccionismo e autoexigência apontados pela maioria dos respondentes da pesquisa denota o quanto os indivíduos se cobram e exigem de si mesmos uma perfeição extrema na entrega das atividades acadêmicas. Essa busca pela excelência e a intensa interferência dos padrões de desempenho e criticismo estão relacionados aos "transtornos de humor, transtorno obsessivo compulsivo e transtornos alimentares, todas elas tendo elevada probabilidade de apresentação de comportamentos suicidas concomitantes" (Egan, Wade \& Shafran, 2011). 


\section{Figura 02}

Fatores que provocam estresse na vida acadêmica Necessidade de participação simultânea em projetos de ensino, pesquisa e extensão.

Ausência de assistência estudantil financeira suficiente Preocupação quanto à colocação profissional Relação com os colegas Relação com os professores Adquirir material de estudo Dificuldades de adaptação Falta de retorno durante o curso Conciliar estudo e lazer Pouco preparo teórico para ingressar na prática Sentimentos de perfeccionismo/autoexigência Excessiva carga de estudo imposta

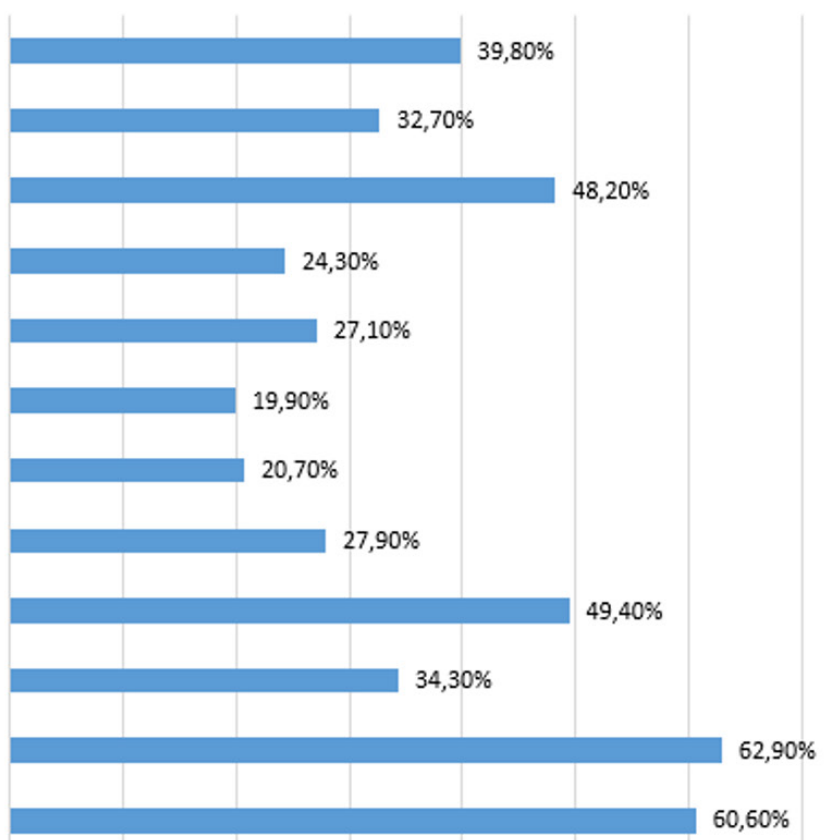

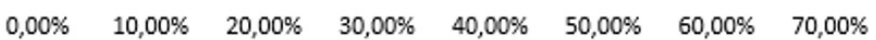

Nota: Elaborado pelos autores

Estudos apontam que o perfeccionismo não é apenas danoso à saúde mental, podendo ser do tipo adaptativo que "é, geralmente, associado a desfechos positivos, como uma boa performance acadêmica e profissional, sendo que o indivíduo costuma de fato alcançar suas metas auto impostas e obter satisfação a respeito disso" (Soares, Rodrigues, Braga, Diniz, Mansur-Alves, 2018, p. 42). Já o perfeccionismo desadaptativo refere-se à desfechos negativos, pois o indivíduo apresenta preocupações demasiadas com os próprios erros, expectativas e crítica dos parentes, amigos, colegas de trabalho, entre outros (Soares et al., 2018).

A excessiva carga horária de estudo imposta pelos professores e a necessidade de participação simultânea em projetos de ensino, pesquisa e extensão também são fatores que podem desenvolver estresse e desconfortos sentimental durante a vida acadêmica.

O meio acadêmico tem um grau de exigência maior do que aquele com o qual o estudante estava acostumado [no ensino médio] e os conteúdos das disciplinas são diferenciados e mais densos, assim o mesmo precisa aprender como conduzir as novas situações que lhe são impostas, caso contrário estas dificuldades podem virar frustrações e, por conseguinte, pensamentos que envolvam desejos de abandono do curso (Pinho, Dourado, Aurélio \& Bastos, 2015, p. 35 [grifo nosso]).

A jornada universitária é composta por um amálgama de atividades a serem desenvolvidas pelos estudantes em parceria com os professores dentro dos pilares de ensino, pesquisa e extensão. As ações curriculares e extracurriculares devem fazer parte da rotina de ambos, de modo que é preciso administrar o tempo e as emoções empreendidos nas atividades. A cada semestre de aula nos cursos de Secretariado Executivo, os estudantes cursam em média 5 disciplinas, as quais demandam diversas tarefas, sobretudo, para avaliar o desempenho acadêmico do aluno. Para conseguir acompanhar e superar as próprias expectativas e dos professores 
na entrega das atividades, os estudantes se submetem a uma carga horária excessiva de estudos, que podem causar estresse e exaustão.

Quando as atividades de pesquisa e extensão são planejadas e executadas juntamente com o ensino, essa carga horária de estudos e trabalho no âmbito do contexto universitário se torna ainda maior. O estudante pode optar em não participar de projetos de pesquisa e extensão, todavia a experiência adquirida nesses espaços proporciona uma aprendizagem efetiva e mais completa na sua formação cidadã e profissional.

\section{Considerações Finais}

Esta pesquisa científica se propôs a investigar se os estudantes do curso de Secretariado Executivo no Brasil têm conhecimento dos sintomas da Síndrome de Burnout. A partir dos dados coletados por meio de questionário, verificou-se que a maioria dos respondentes não tinham conhecimento sobre essa síndrome. Percebe-se que, ainda, há pouca divulgação dos sintomas dessa síndrome no âmbito acadêmico, de forma que os indícios desse distúrbio mental podem passar despercebidos.

Como objetivo específico deste estudo de campo, identificou-se os sintomas da síndrome de Burnout que foram adquiridos pelos estudantes de Secretariado Executivo de diversas instituições brasileiras após o ingresso na universidade, sendo eles: ansiedade, cansaço, sensação de esgotamento físico com irritabilidade, sentimento de incapacidade ou inferioridade. Todavia, cabe ressaltar os sintomas que não tiveram altos índices de ocorrência nos sujeitos da pesquisa, porque eles merecem atenção da comunidade acadêmica afim de promover ações preventivas. São eles: alteração do sono, falta de motivação, dificuldades de concentração, fadiga, lapsos de memória, entre outros que são apresentados na figura 2.

Visando conhecer as razões que causam mais estresse na vida dos universitários de Secretariado Executivo, questionou-se os fatores que são considerados mais impactantes e obtive-se as seguintes respostas: sentimentos de perfeccionismo/autoexigência, excessiva carga de estudo imposta, conciliar estudo e lazer, preocupação quanto à colocação profissional, necessidade de participação simultânea em projetos de ensino, pesquisa e extensão. Em menor escala, os estudantes afirmaram que o pouco preparo teórico para ingressar na prática, a ausência de assistência estudantil financeira suficiente, falta de retorno durante durante o curso, bem como a relação com os professores e os colegas também são fatores que podem causar distúrbios mentais.

Por fim, os estudantes de Secretariado Executivo informaram se a sua instituição de ensino disponibiliza algum serviço de suporte e apoio psicológico, de maneira que a maioria dos respondentes afirmaram que existe algum tipo suporte na universidade. Percebe-se, então, que algumas instituições têm se atentado para o lado emocional e psíquico da comunidade acadêmica, passando a intervir para prevenir ou reparar os possíveis danos à saúde mental apresentados.

Reafirma-se a importância desse estudo para profissão de Secretariado Executivo, já que não foram encontradas outras publicações que tenham investigado a Síndrome de Burnout nos estudantes e profissionais desta categoria profissional. Os resultados podem servir de apoio aos docentes para que possam (re)planejar 
suas avaliações de forma interdisciplinar, além de subsidiar dados às universidades para promoverem ações de prevenção e promoção da saúde física e mental do público universitário.

Para pesquisas futuras, recomenda-se o mapeamento dos níveis de estresse que são causados pelas atividades de avaliação estabelecidas pelos professores em seus componentes curriculares, com o intuito de verificar as atividades que causam mais desconfortos mentais físicos e estresse. É preciso, então, que os professores percebam os sinais que são emanados pelos estudantes a partir do seu envolvimento com as atividades e a qualidade em que elas são apresentadas, pois a sobrecarga de estudos e atividades acadêmicas podem gerar transtornos psicológicos, a exemplo da síndrome de Burnout.

Sugere-se, também, que os docentes dos cursos de Secretariado Executivo sejam o público-alvo de pesquisas científicas em torno da síndrome de Burnout, já que eles também têm uma elevada carga horária de trabalho, um dos motivos para que os sintomas desta síndrome sejam desenvolvidos. 


\section{Referências}

Albornoz, A. C. G. (2016). Avaliação Psicológica nos Transtornos de Ansiedade: Estudos Brasileiros.

Porto Alegre. Recuperado em 02 março, 2020, de https://www.lume.ufrgs.br/bitstream/ handle/10183/147064/000998195.pdf?sequence=1.

Bardagi, M. P. \& Hutz, C. S. (2012). Rotina acadêmica e relação com colegas e professores: Impacto na evasão universitária. Psico, 43(2), 174-184.

Barbosa, F. de O., Macedo, P. C. M., \& Silveira, R. M. C. (2011). Depressão e Suicídio. Rev. SBPH, Rio de Janeiro, 14(1). Benevides-Pereira, A. M. T. (2003). O Estado da Arte do Burnout no Brasil. Revista Eletrônica InterAçãoPsy, Maringá, 1(1), 4-11.

Decreto no 7.234, de 19 de julho de 2010. (2010). Dispõe sobre O Programa Nacional de Assistência Estudantil - Pnaes. Brasília-DF. Recuperado em 03 março, 2020, de http://www.planalto.gov.br/ccivil 03/ Ato20072010/2010/Decreto/D7234.htm.

Carlotto, M. S. \& Câmara, S. G. (2008). Preditores da Síndrome de Burnout em estudantes universitários. Pensamiento Psicológico, 4(10), 101-109.

Cavalcante, R. B., Calixto, P. \& Pinheiro, M.M.K. (2014). Análise de Conteúdo: considerações gerais, relações com a pergunta de pesquisa, possibilidades e limitações do método. Inf. \& Soc. Est., João Pessoa, 24(1), 13-18.

Christofoletti, G., Trelha, C. S, Galera, M. R., \& Feracin, M.A. (2007). Síndrome de Burnout em acadêmicos de Fisioterapia. Fisioterapia e Pesquisa, São Paulo, 14(2), 35-39.

Egan, S. J., Wade, T. D. \& Shafran, R. (2011). Perfectionism as a transdiagnostic process: A clinical review. Clinical Psychology Review, 31(2), 203-212.

Ferreira, F. (2016). A importância da inteligência emocional no contexto organizacional. Anais do Congresso Nacional de Excelência em Gestão, Rio de Janeiro, RJ, Brasil. Recuperado em 04 março, 2020, de http:// www.inovarse.org/node/4751

Galindo, R. H., Feliciano, K. V. O., Lima, R. A. S., \& Souza, A. I. (2012). Síndrome de Burnout entre enfermeiros de um hospital geral da cidade do Recife. Revista da Escola de Enfermagem da USP, São Paulo, 46(2), 420-427.

Garcia L. P. \& Benevides-Pereira A. M. T. (2003). Investigando o Burnout em professores universitários. Revista Eletrônica Interação, Maringá, 1(1), 76-89.

Gerardin Júnior, U., Monteiro, A. A., \& Gianini, V. C. (2011). Currículos de secretariado executivo: algumas reflexões. R. G. Secr., GESEC, São Paulo, 2(2), 58-78.

Gil, A. C. (2006). Métodos e técnicas de pesquisa social (5a ed.). São Paulo: Atlas.

Goleman, D. (2015). Liderança: a inteligência emocional na formação do líder de sucesso. Rio de Janeiro: Objetiva.

Goleman, D. (2011). Inteligência emocional: A teoria revolucionária que redefine o que é ser inteligente. Rio de Janeiro: Objetiva. 
Guimarães, E. R. (2014). A Síndrome de Burnout em estudantes de ciências contábeis: pesquisa na cidade de São Paulo. Dissertação de mestrado, Programa de Pós-graduação em Ciências Contábeis, Centro de Ciências Contábeis, Fundação Escola de Comércio Álvaro Penteado, São Paulo, SP, Brasil.

Leal, D. \& Antunes, M. A. M. (2015). Compensação e deficiência no pensamento de Alfred Adler (1870-1937). Memorandum, 29, 13-33.

King, J. L. (2016). Inteligência Emocional: Trabalhando com Inteligência Emocional para Melhorar a Gestão da Raiva: Descubra como as Emoções são Feitas e Controladas. Ebook Kindle. [S.L.]: Amazon.

Maslach, C. \& Jackson, S. E. M. (1981). Burnout Inventory. Palo Alto: Consulting Psychologists Press.

Mota, Í. D., Farias, G. O. Silva, R., \& Folle, A. (2017, dezembro). Síndrome de Burnout em Estudantes Universitários: um olhar sobre as investigações. Motrivivência, Florianópolis/SC, 29(n. esp.), 243-256.

Palazzo, L. dos S., Carlotto, M., S., \& Aerts, D. R. G. de C. (2012). Síndrome de Burnout: estudo de base populacional com servidores do setor público. Rev. Saúde Pública [online]. 46(6), 1066-1073.

Pinho, A. P. M., Dourado, L. C., Aurélio, R. M., \& Bastos, A. V. B. (2015). A Transição do Ensino Médio para a Universidade: Um Estudo Qualitativo sobre os Fatores que influenciam este processo e suas Possíveis Consequências Comportamentais. Revista de Psicologia, Fortaleza, 6(1), 33-47.

Ribeiro, J., Honrado, A., \& Leal, I. (2004). Contribuição para o estudo da adaptação portuguesa das escalas de ansiedade, depressão e stresse (EAD). Psicologia, Saúde \& Doenças, 5(2), 229-239.

Rocha, F. \& Santos, G. (2014). Síndrome de Burnout em Profissionais da Saúde. Recuperado em 20 julho, 2020, de http://www.hospitaldecataguases.com.br/wp-content/uploads/2017/04/Sindrome_de_Burnout.pdf

Silva, D., Lopes, E., \& Braga Junior, S. (2014). Pesquisa Quantitativa: Elementos, Paradigmas e Definições. R. G. Secr., GESEC, São Paulo, 5(1), 01-18. https://doi.org/10.7769/gesec.v5i1.297

Soares, F. H., Rodrigues, W. de S., Braga, A. C. G., Diniz, M. L. N. \& Mansur-Alves, Marcela. (2018). Perfeccionismo como fator de vulnerabilidade para a suicidalidade, (pp. 39-52). In Godoy, V. P. Suicídio: compreender, identificar e intervir. São Paulo: Sociedade Brasileira de Neuropsicologia.

Tavares, S. M. (2002). Guia Einsten para portadores de deficiência visual: a importância do sono. São Paulo: Instituto de ensino e pesquisa Albert Einsten.

Thurber, A. \& Walton, E. (2007). Preventing and treating homesickness. Official Journal of the American Academy of Pediatrics, 192-194.

Teixeira, N. (1960). Alguns Aspectos da Problemática Médico-Social do Complexo de Inferioridade. Revista da Faculdade de Direito UFPR, 8.

Valle, C. A. (2016). Inteligência emocional: aprenda a se comunicar e controlar melhor suas emoções para se comunicar melhor e multiplicar suas competências sociais e sucessos na vida. [S. L.]: Amazon.

Weisinger, H. (2001). Inteligência emocional no trabalho: como aplicar os conceitos revolucionários da I. E. nas suas relações profissionais, reduzindo o estresse, aumentando sua satisfação, eficiência e competitividade. Rio de Janeiro: Objetiva. 
Zuardi, Antonio. (2017). Características básicas do transtorno do pânico. Medicina (Ribeirão Preto, Online.), 56-63. 